\title{
SYPHILIS IN RELATION TO THE ETIOLOGY AND DIAGNOSIS OF MALIGNANT DISEASE
}

\section{Discussion}

The President said the members present would wish to express to Dr. Leitch their very great appreciation of his extraordinarily interesting address.

His own impression was that it was very rare to see squamous-celled carcinoma developing as the result of chronic syphilitic lesions of the skin or of sinuses going down to necrosed bone, and that it was even rarer than carcinoma secondary to the chronic irritation of other lesions of the skin, such as keloid, or in connection with lupus, such as Sir Jonathan Hutchinson described years ago. A point brought out by Dr. Leitch was that squamous-celled carcinoma developed more often than columnar or spheroidal-celled carcinoma in syphilitic subjects; for instance, there was a contrast between squamous epithelioma of the tongue and malignant disease of the stomach. Reference had also been made to the possible action of syphilis in reducing the resistance of tissues, so that epithelial cells could spread into the deeper parts with greater readiness. Was it possible that previous syphilis acted on columnar cells and impaired their activity more efficiently than on squamous cells? The figures as to carcinoma of the cervix lent support to the idea that squamous-celled carcinoma was more often associated with the positive Wassermann than other forms of carcinoma. Dr. Leitch did not refer to sweep's cancer of the scrotum, except that it could be included in the cancer of occupations. He agreed as to the occurrence of stricture of the œsophagus in persons known to have syphilis, for his experience in the postmortem room was that patients thought to have syphilitic stricture of the œesophagus really had squamous-celled carcinoma. The condition formerly spoken of as syphilitic 


\section{BRITISH JOURNAL OF VENEREAL DISEASES}

stricture of the rectum, and more recently as hyperplastic tuberculosis comparable to what took place in the cæcum and vermiform appendix, was now said by a writer in an American journal to be due not to the tubercle bacillus, but to be a simple chronic granuloma. Another point was whether there was anything to support the statement of two Italian pathologists that in carcinoma of the liver there might be, as a result, a positive Wassermann, nothing else being present to suggest that the person had syphilis. Dr. J. W. McNee had published two cases in which gumma of the stomach imitated carcinoma of that organ. He (the speaker) had always thought that chronic ulcer of the stomach might occur more often in patients with syphilitic endarteritis of the gastric arteries than in ordinary persons; and in a certain proportion of cases chronic ulcer of the stomach was succeeded by carcinoma.

Colonel HARrison (who at this stage took the chair) repeated Sir Humphry Rolleston's appreciation of Dr. Leitch's paper, and said he had equally enjoyed that gentleman's masterly analysis of the figures. Previously the subject had been dealt with somewhat diffusely, but now there was something tangible.to go upon, and he was sorry more members were not present to enjoy the discussion.

He would like to suggest that the binding factor connecting the two conditions, syphilitic infiltration and cancer, was chronic irritation. It was known that syphilis tended to recur at a spot which had sustained damage; good evidence of that was afforded by chronic syphilitic glossitis, a condition rarely seen in women, for the probable reason that women did not imbibe and inhale mouth irritants so much as did men. How far that would remain true in the future, seeing how much women were taking to smoking and short drinks, remained to be seen. The tongue, which was the seat of chronic syphilitic glossitis, was in a chronic state of irritation, an ideal state for the supervention of cancer. This irritation factor had been strongly impressed upon him by the case of the Kashmiri. In cold weather these people carried under their shawls fire-baskets which they pressed against their abdomens, to keep themselves warm, and epithelioma of the abdominal wall was common amongst them. Syphilitic ulcers on other parts of the body were rarely, 


\section{DIAGNOSIS OF MALIGNANT DISEASE}

he thought, followed by cancer, but every one would agree as to the close relationship of syphilis of the tongue and cancer of that organ.

The subject of syphilis of the cervix had not been very well worked out, but he did not see why there should not occur the train of a diffuse syphilitic infiltration of the cervix, an irritated mucous membrane, as in the tongue, and eventually an epithelioma.

The Chairman (Colonel Harrison), in proposing a cordial vote of thanks to Dr. Leitch, suggested that if in the experiments with heat on the animals instead of a copper heater a similar fire container to that employed by the Kashmiris, a baked clay bowl, had been used, cancer might have resulted, as it was possible the heated clay was the specific irritant. He remembered being taught that there seemed to be a connection between epithelioma of the lip and the smoking of short clay pipes.

The resolution was carried by acclamation.

Dr. DAvid NABARRo, after thanking Dr. Leitch for his paper, said that most of his work was connected with children; therefore the question of epithelioma scarcely came in. He recalled only one case of sarcoma in a child, one in a thousand cases of congenital syphilis, and that meant nothing as an ætiological factor.

He noticed that in the figures given Dr. Leitch always relied on the Wassermann positive reaction as evidence of syphilis, but that the speaker did not think was quite safe. Frequently one got a negative Wassermann in fathers of children who were known to be syphilitic ; it was so in 70 per cent. of his own congenitally syphilitic cases. Often, too, one could not get a history of syphilis. That very day he had interviewed a father whose Wassermann was returned as positive, yet he assured the speaker that he had never had a primary chancre or a rash, and this story he adhered to under repeated questioning. Therefore the figures given by Dr. Leitch might really be an understatement of the case.

He did not know whether Dr. Leitch gave the figures relating to cancer of the body of the uterus, because it had been suggested that the mothers of syphilitic children might have a mild local infection with the spirochæte in the body of the uterus. If this frequently happened, and if syphilis predisposed to cancer, then cancer of the body of the uterus should be much commoner than it was. 


\section{BRITISH JOURNAL OF VENEREAL DISEASES}

Dr. Doble agreed that the Society was very grateful to Dr. Leitch for this contribution. It would be a great help in arriving at a conclusion if the number of people in the country with a positive Wassermann reaction were known. In Uganda the proportion was given as from 80 to 98 per cent., yet malignant disease was practically unknown there.

With regard to gastric ulcer, he remembered four cases who had a positive Wassermann. They were treated, and two years later the Wassermann was negative, and no gastric trouble occurred since. If syphilis were a precursor of cancer, it must be the tertiary form ; if it were primary, cancer of the penis would be common, yet he had seen only one case of epithelioma of the penis, and that man's Wassermann was negative.

Recently he had examined the blood of two patients who had malignant disease of the œsophagus. One had a negative Wassermann, the other a positive. The latter was very vigorously treated, but without effect, and the patient died in two months.

Epithelioma of the lower lip was very common in Cornwall, a county in which syphilis was very rare. $\mathrm{He}$ had fourteen cases of epithelioma in that site; the growth was cut out and microscoped, and in every case the Wassermann was negative.

He felt sure that one cause of epithelioma of the mouth and tongue was smoking, especially the use of a short clay pipe; but in the case of fishermen it was probably due to the irritation of tarred fishing-lines, which they held in their mouth, and when a bite occurred, there was a strain on the lips.

Dr. SHARP said that carcinoma of the body of the uterus was rare in parous women ; it was more common in nulliparous women. That was against the idea that infection of the endometrium in a woman who had given birth to syphilitic children was a predisposing cause of cancer.

Dr. LeITCH, replying on the discussion, said he felt much indebted for the attention which had been given to his somewhat discursive remarks. He was glad to learn that the general impression was that syphilitic lesions, other than those of the tongue, were not specially prone to degenerate into malignant disease. His own views coincided with those expressed by the President and by 


\section{DIAGNOSIS OF MALIGNANT DISEASE}

Colonel Harrison. And he had been much interested in the President's point as to the possible relation of syphilis to cancer of the stomach through endarteritis of the gastric arteries and degeneration, with subsequent ulceration. In this country probably Io per cent. of chronic gastric ulcers became malignant.

He was unaware of the Italian observations on the incidence of positive Wassermann reactions in cancer of the liver. As primary liver cancer was almost invariably associated with cirrhosis, it might be that syphilis as a cause of the latter would have to be more seriously considered.

The point made as to syphilis occurring on a damaged spot was of great interest. The irritation theory of cancer was now more than a speculation. In susceptible animals cancer could be produced at will by tar, pitch, arsenic, mineral oil, soot, etc. ; but for every agent in which success was obtained one could be sure there were at least a score of failures. So it was not merely irritation in general that caused the cancers. There was something more or less specific in the irritant. In most cases of cancer, however, there was nothing which could be suspected in the way of external irritants, but arguing from analogy, one might suspect that malproducts of metabolism due to diseased processes would have the same effect as the known carcinogenic irritants.

He had been glad to hear from one who had had experience of the abdominal cancer of the Kashmiris ; previously his information on the subject had been obtained by reading. Some said the cancer was not due to the heat, but to the products of combustion, but the speaker did not agree with that. Experiments on the matter had been done on animals, by means of a thermo-cautery, without actually touching the skin, so that a mere erythema was produced, but he had never succeeded in inducing tumour formation.

Among the negroes of Baltimore there was an enormous amount of syphilis, but among them Cary could not find any cases of epithelioma of the tongue.

The uterus cases he mentioned were all cervix cases. In the body of the uterus cancer was said to be rare in parous women as contrasted with nulliparous, but a statistical study he had made did not bear that out. Cancer of the body of the uterus was said to progress 


\section{BRITISH JOURNAL OF VENEREAL DISEASES}

slower than cancer of the cervix, but histories of cases did not show any difference in that, nor in the lymphatic spread.

The great difficulty was in diagnosing epithelioma of the tongue from syphilis of the tongue ; the Wassermann reaction did not help in this. Unless there were a section of a tongue available, he would be very chary to trust any diagnosis except in an advanced case. 